\title{
Linguística Aplicada \& Lexicografia Pedagógica: intersecções possíveis por meio da Linguística de Corpus
}

\author{
Applied Linguistics \&Pedagogical Lexicography: possible intersections through \\ Corpus Linguistics
}

\author{
Daniela Faria Grama* \\ Neubiana Silva Veloso Beilke*
}

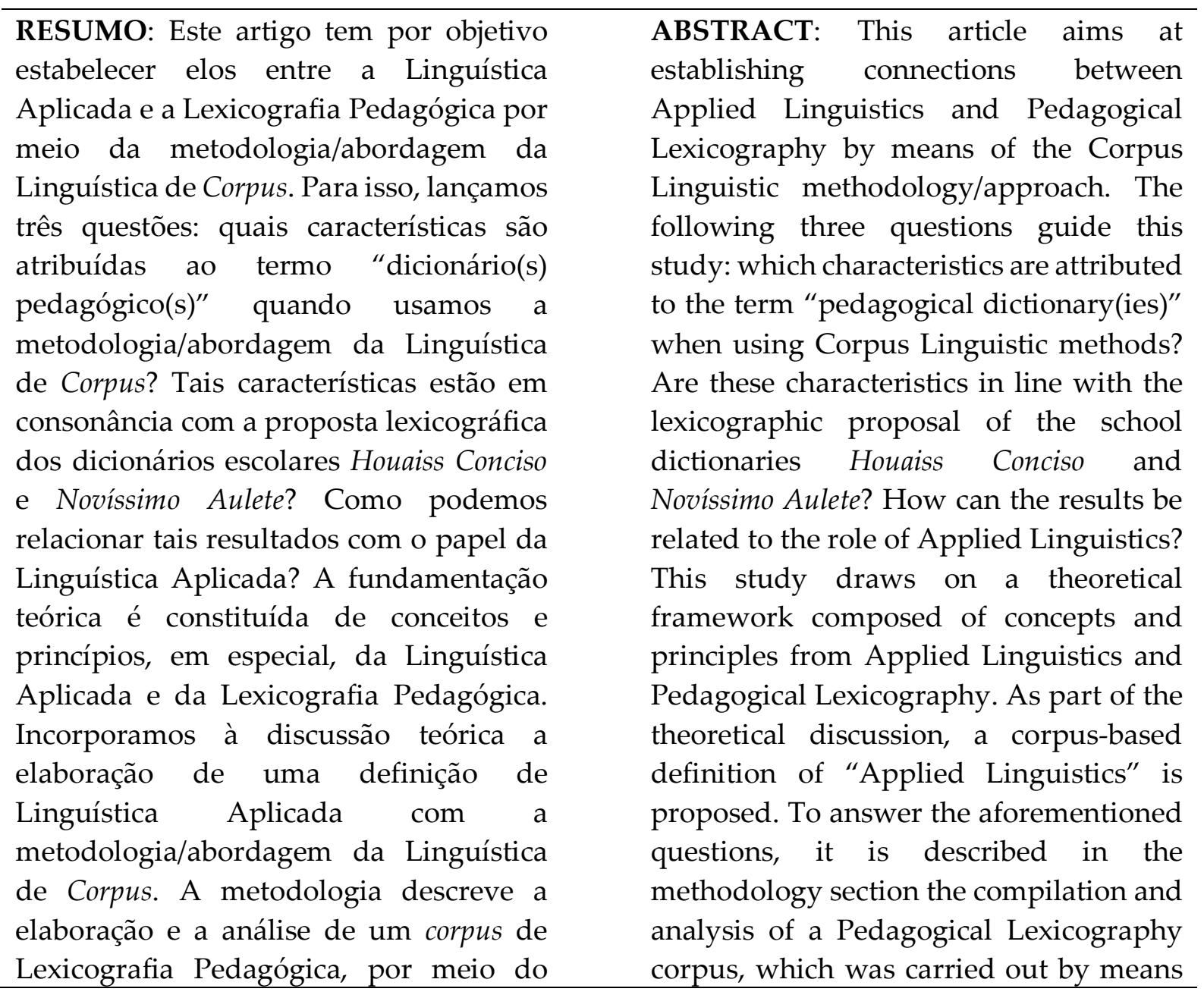

*Doutoranda do Programa de Pós-Graduação em Estudos Linguísticos (PPGEL) da Universidade Federal de Uberlândia (UFU). daniela grama@hotmail.com.

**Doutoranda do Programa de Pós-Graduação em Estudos Linguísticos (PPGEL) da Universidade Federal de Uberlândia (UFU). neubeilke@hotmail.com. 
programa WordSmith Tools, versão 6, para respondermos às três questões. Na seção de análises e resultados, as características relativas ao termo "dicionário(s) pedagógico(s)" são identificadas e tornam-se base para análise do Novíssimo Aulete e do Houaiss Conciso. Percebemos que tais obras possuem poucas das características elencadas como próprias de um dicionário pedagógico.

PALAVRAS-CHAVE: Linguística Aplicada. Lexicografia Pedagógica. Linguística de Corpus. of the software WordSmith Tools 6.0. In the analysis and results section the characteristics related to the term "pedagogical dictionary(ies)" are identified and used as a basis for the analysis of Novíssimo Aulete and of Houaiss Conciso. It has been perceived that such dictionaries have few characteristics pertaining to pedagogical dictionaries.

KEYWORDS: Applied Linguistics. Pedagogical Lexicography. Corpus Linguistics.

\section{Introdução}

Neste artigo, propomo-nos a mostrar alguns pontos de encontro entre a Linguística Aplicada e a Lexicografia Pedagógica por meio da metodologia/abordagem da Linguística de Corpus. Para isso, elaboramos as seguintes questões: quais características são atribuídas ao termo “dicionário(s) pedagógico(s)" quando usamos a metodologia/abordagem da Linguística de Corpus? Tais características estão em consonância com a proposta lexicográfica dos dicionários escolares Tipo 4 Houaiss Conciso e Novíssimo Aulete? Como podemos relacionar tais resultados com o papel da Linguística Aplicada?

Ressaltamos que a motivação para iniciarmos este trabalho tem por base o fato de a Lexicografia Pedagógica ser, conforme Krieger (2011), uma área ainda recente no Brasil e que necessita de pesquisas e estudos para que possa produzir produtos, dicionários pedagógicos, cada vez mais bem elaborados. Assim, é importante observarmos quais são as características dos tipos de obras consideradas como pedagógicas de acordo com o respaldo teórico já produzido no Brasil sobre Lexicografia Pedagógica. De acordo com Krieger, “é importante para a Lexicografia Pedagógica oferecer subsídios para tornar o uso do dicionário produtivo e orientado para o ensino e aprendizagem de línguas" (KRIEGER, 2012, p. 173). Além disso, este 
trabalho também se justifica por termos percebido vários pontos de encontro entre a Lexicografia Pedagógica e a Linguística Aplicada e também por considerarmos importante a divulgação dos métodos e procedimentos que a Linguística de Corpus propicia a um pesquisador.

Este artigo é composto por cinco seções. A primeira diz respeito a esta introdução, que esclarece, brevemente, as questões iniciais deste trabalho. A segunda refere à apresentação da fundamentação teórica, que é constituída de conceitos e princípios, em especial, da Linguística Aplicada e da Lexicografia Pedagógica. Na seção em questão, elaboramos uma definição de Linguística Aplicada com a metodologia/abordagem da Linguística de Corpus e estabelecemos elos entre a Linguística Aplicada e a Lexicografia Pedagógica. A terceira alude à descrição da metodologia utilizada para chegarmos às respostas das questões lançadas nesta introdução. A quarta diz respeito aos resultados e análises aos quais chegamos a partir da metodologia, com o intuito de respondermos às questões lançadas nesta introdução; e a quinta refere às considerações finais deste trabalho.

\section{Fundamentação teórica}

Nesta seção, focamos no conceito de Linguística Aplicada e nos princípios da Lexicografia Pedagógica, estabelecendo elos entre ambas.

\subsection{Linguística Aplicada}

A Linguística Aplicada (doravante LA) não possui fronteiras rígidas, ou seja, é caracterizada pelo não-limite, por não ser estanque. Isso significa que suas fronteiras são móveis dentro daquilo que os linguistas aplicados fazem efetivamente dela. Ressalvamos, de antemão, que não consideramos a LA como mera aplicação de teorias ao ensino. Podemos dizer que ela parte da identificação de um problema que envolva o uso de linguagem e que procura recursos teóricos e metodológicos para trazer uma 
contribuição à sociedade. Vale ressaltar que ela não se limita aos problemas que envolvem o ensino de línguas, mas também abrange questões relativas a áreas tais como: Linguística Forense, Lexicografia, Terminografia, entre outras.

Para Cavalcanti (1986 apud BRITO, p. 11), a LA é multidisciplinar em sua preocupação com questões de uso de linguagem, possui objeto de estudo, princípios e metodologia próprios, já tendo inclusive começado a desenvolver modelos teóricos. Ingram (1980, apud BRITO, p. 11) também reconhece certa autonomia na LA, por ela construir seus próprios princípios a partir de experimentação e de modificações na solução de problemas relacionados à linguagem.

Rojo (2006, p. 264) acredita que a transdisciplinaridade é característica fundamental e necessária da LA, na medida em que esta permite que outros conhecimentos sejam mobilizados para a compreensão de processos; é a dinâmica de reconstrução, de rearticulação e de ressignificação dos conceitos e interpretações, que não devem ser meramente aplicados aos dados, mas avaliados com base no objeto de estudo e no problema a ser trabalhado. Segundo a referida autora, os problemas de linguagem dos sujeitos criam o(s) objeto(s) de investigação e permitem delinear configurações teórico-metodológicas próprias a cada caso, é o que Rojo (2006, p. 264) chama de "percursos transdisciplinares de investigação".

Assim, com base em Moita Lopes (1996) e em Rojo (2006), podemos dizer que a LA produz conhecimento a partir do momento em que busca solução para problemas socialmente relevantes em um contexto de aplicação específico, ou seja, é um conhecimento voltado para a prática social.

Tendo em vista o caráter transdisciplinar da LA, depreendemos que ela abrange diversificados objetos de análise que estabelecem relações com diferentes disciplinas, permitindo a formulação de teorias. Conforme Serrani (1990 apud ROJO, 2006), a LA atravessa as fronteiras das disciplinas; estas não são meras fornecedoras de subsídios, pois, ainda que se busque dialogar com conceitos de diferentes áreas como 
Antropologia, Sociologia, História etc., os conceitos são ressignificados, rearticulados, com base nas exigências do objeto de estudo em questão, não sendo reproduzidos de maneira fixa em relação ao seu contexto de origem. Por isso, Rojo (2006), que define a LA como um campo de estudos e pesquisas, tenta nos mobilizar a não estabelecer limites teóricos pesados nem fixos para enfrentar os problemas de linguagem, que são também problemas sociais.

Somando ao que foi exposto, acreditamos que a Linguística de Corpus (doravante LC) também pode contribuir para a construção de uma conceituação sobre a LA, pois a LC baseia-se em um conjunto de textos escritos advindos de determinada área (no nosso caso, da área de LA), provenientes de contextos de usos autênticos. Tais contextos permitem a extração de traços distintivos referentes ao alvo de conceituação (no nosso caso, o alvo é o conceito de LA) da área do conhecimento que se pretende pesquisar. A partir dos traços distintivos, podem ser formulados conceitos com base nos traços extraídos dos contextos definitórios e/ou explicativos.

Para construirmos uma definição de LA com o método da LC, obtivemos um corpus de Linguística Aplicada, reunido de modo criterioso, por meio de uma coleção de textos acadêmicos da área - artigos extraídos de revistas especializadas em LA e também teses e dissertações da área. O corpus foi compilado por Fromm e seus alunos para a disciplina de Lexicologia/Lexicografia entre os anos de 2012 a 2014. Esse corpus, aqui intitulado como Corpus LA, atinge 201.247 types ou formas distintas (palavras sem repetições) e 12.326.716 tokens ou formas corridas (palavras com repetições).

Para processamento do Corpus LA, utilizamos a Trial Version (versão gratuita por 30 dias) do Sketch Engine, que é uma ferramenta de compilação de corpus e de análise lexical disponível online. O passo seguinte foi gerar linhas de concordância com a entrada-chave "Linguística Aplicada" para buscar contextos definitórios e/ou explicativos, conforme é possível visualizar na Figura 1 a seguir: 
Figura 1 - Linhas de concordâncias para "Linguística Aplicada" no Sketch Engine.

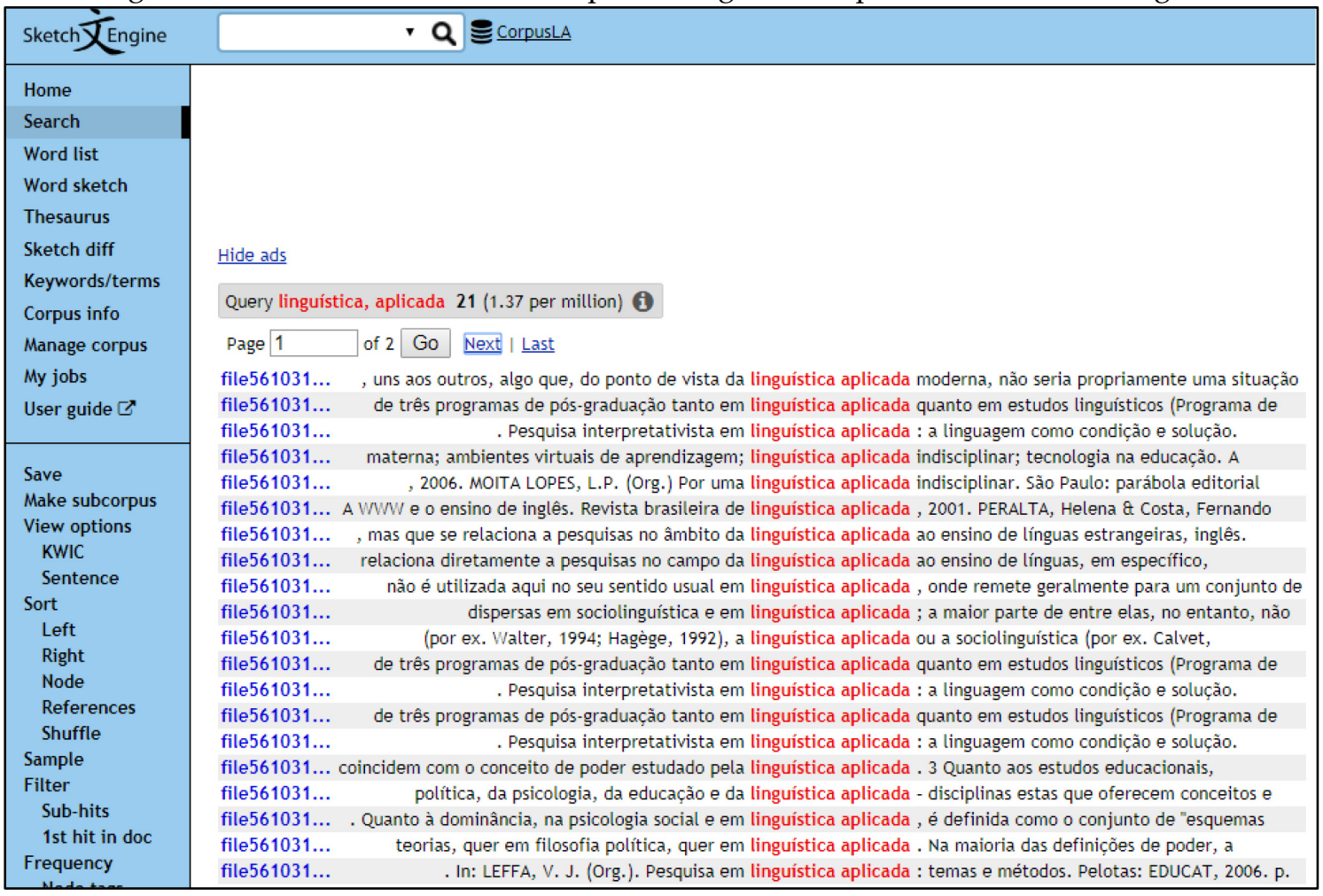

Fonte: elaboração própria.

O terceiro passo foi realizar a leitura qualitativa dos contextos e selecionar aqueles que continham traços definitórios e também traços distintivos explicativos que caracterizassem a LA a fim de permitir sua conceituação. Feito isso, passamos à construção da definição no Votec - Vocabulário Técnico Online (FROMM, 2007), que é um ambiente de gestão terminográfica online escolhido por nos permitir criar a definição utilizando os traços mencionados e com base na definição aristotélica ${ }^{1}$. Esta etapa da construção da definição pode ser visualizada por meio da Figura 2 a seguir:

\footnotetext{
${ }^{1}$ Conforme Welker (2004), a definição aristotélica se resume em utilizar um gênero próximo e diferenças específicas.
} 
Figura 2 - Construção da definição de "Linguística Aplicada" na tela do Votec.

\begin{tabular}{|c|c|c|c|c|c|c|c|c|c|}
\hline \multicolumn{10}{|c|}{$\begin{array}{l}\text { Contextos Conceito Final / Definição } \\
\text { Contextos }\end{array}$} \\
\hline & \multicolumn{3}{|l|}{ Exemplo } & \multicolumn{4}{|l|}{ Conceito } & \multicolumn{2}{|l|}{ Fonte } \\
\hline 1 & \multicolumn{3}{|c|}{$\begin{array}{l}\text { A linguística aplicada é um campo que oferece } \\
\text { e investiga soluções para problemas } \\
\text { relacionados ao uso da linguagem na vida } \\
\text { real. Esta nova área é definida por Brumfit } \\
\text { (1995, p. 27) como "investigação empírica e } \\
\text { teórica de problemas do mundo real nos quais } \\
\text { a linguagem é uma questão central". }\end{array}$} & \multicolumn{4}{|c|}{$\begin{array}{l}\text { campo; investiga soluções para problemas } \\
\text { relacionados ao uso da linguagem na vida real; } \\
\text { área; investigação empírica e teórica de } \\
\text { problemas do mundo real nos quais a } \\
\text { linguagem é uma questão central }\end{array}$} & \multicolumn{2}{|c|}{ PDF 02/12/2017 } \\
\hline 2 & \multicolumn{3}{|c|}{$\begin{array}{l}\text { [...]pesquisamos várias teorias da filosofia } \\
\text { política, da psicologia, da educação e da } \\
\text { linguística aplicada - disciplinas estas que } \\
\text { nfererem rnnreitoc e vieces nı сө }\end{array}$} & \multicolumn{4}{|c|}{$\begin{array}{l}\text { teoria; disciplinas; oferecem conceitos e } \\
\text { vieses; horizonte de referência para pesquisa; } \\
\text { multidimensional; transdisciplinar; modelos } \\
\text { elahnradoc }\end{array}$} & \multicolumn{2}{|c|}{ PDF 02/12/2017 } \\
\hline \multirow{2}{*}{\multicolumn{10}{|c|}{ Informaçốes Enciclopédicas }} \\
\hline & & & & & & & & & \\
\hline \multicolumn{10}{|c|}{ Nova Coluna - Não use aspas duplas } \\
\hline & A & B & C & D & E & $F$ & \multicolumn{2}{|l|}{$G$} & H \\
\hline 1 & campo & investiga ... & área & \multicolumn{2}{|l|}{ investigaç... } & & & & \\
\hline 2 & teoria & & disciplina... & norizonte ... & oferecem c... & multidimen... & \multicolumn{2}{|c|}{ transdisci... } & modelos el... \\
\hline 3 & parâmetros... & & & intervençã... & & altamente ... & & & não precis... \\
\hline 4 & área cient... & & & esforço de... & & & & & \\
\hline 5 & aplicação ... & & uma das mo... & área de es... & & & & & \\
\hline 6 & como a apl... & & & \multirow[t]{2}{*}{ a questão ... } & & & \multicolumn{2}{|c|}{ LA de uma ... } & \\
\hline & & & & & & & & \\
\hline
\end{tabular}

Fonte: elaboração própria.

Por fim, obtivemos a definição de Linguística Aplicada com base no Corpus LA por meio da metodologia da LC. Conforme, podemos observar na Figura 3 a seguir:

Figura 3 - Definição de "Linguística Aplicada" publicada e exibida no Votec.

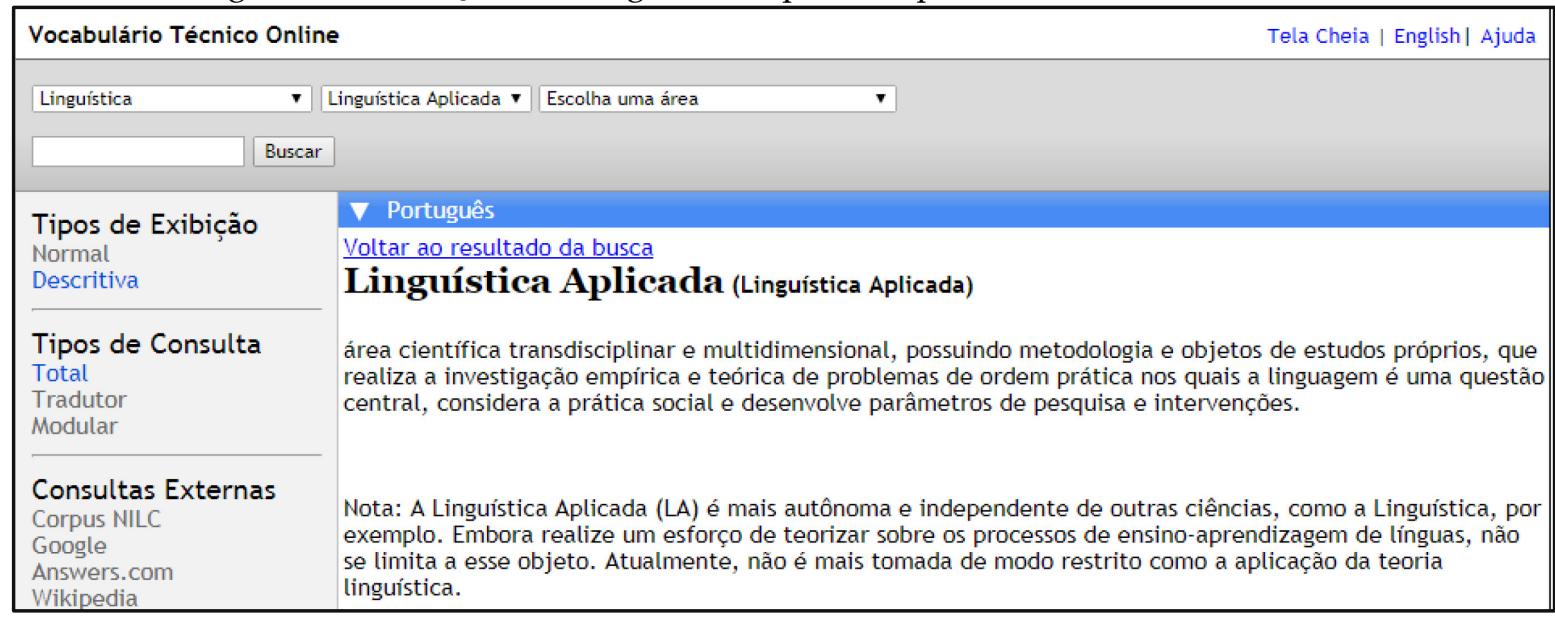

Fonte: elaboração própria. 
Transcrevemos aqui a definição final de LA que construímos com base no Corpus LA:

área científica transdisciplinar e multidimensional, possuindo metodologia e objetos de estudos próprios, que realiza a investigação empírica e teórica de problemas de ordem prática nos quais a linguagem é uma questão central, considera a prática social e desenvolve parâmetros de pesquisa e intervenções (VOTEC, 2017).

Percebemos que entre as características apresentadas pelos autores mencionados nesta seção e a definição a que chegamos por meio da observação de uma grande quantidade de textos da área da LA há alguns traços que caracterizam tal área, como a transdisciplinaridade e o foco na solução de problemas de linguagem de ordem prática. Além disso, a questão da relevância social e da capacidade de desenvolver metodologias e parâmetros próprios também foi recorrente. Deste modo, observamos que não obtivemos uma definição coincidente, porém coerente com o que os autores referidos nesta seção mencionam.

Em suma, podemos dizer que a LA é uma área de produção de conhecimentos práticos que exigem constante reflexão sobre métodos, com foco em resultados, e não em teorias de base, uma vez que estas são mobilizadas a partir de diversas áreas e ressignificadas. Assim, novos constructos teóricos vão surgindo para dar conta da complexidade que os objetos de estudo pedem, a fim de se encontrarem soluções eficazes para problemas de linguagem da vida social e de contribuir socialmente, utilizando nossa área (a da Linguística) articulada a diversos outros saberes. $\mathrm{Na}$ sequência, apresentamos alguns pontos teóricos que se relacionam quando nos referimos à Linguística Aplicada, à Lexicografia Pedagógica e à Linguística de Corpus. 


\subsection{Interseções entre Linguística Aplicada, Lexicografia Pedagógica e Linguística de Corpus}

A Lexicografia Pedagógica é um ramo da Lexicografia que, por sua vez, inserese na Linguística Aplicada, conforme Fromm (2015):

Figura 4 - Árvore de domínio da Linguística.

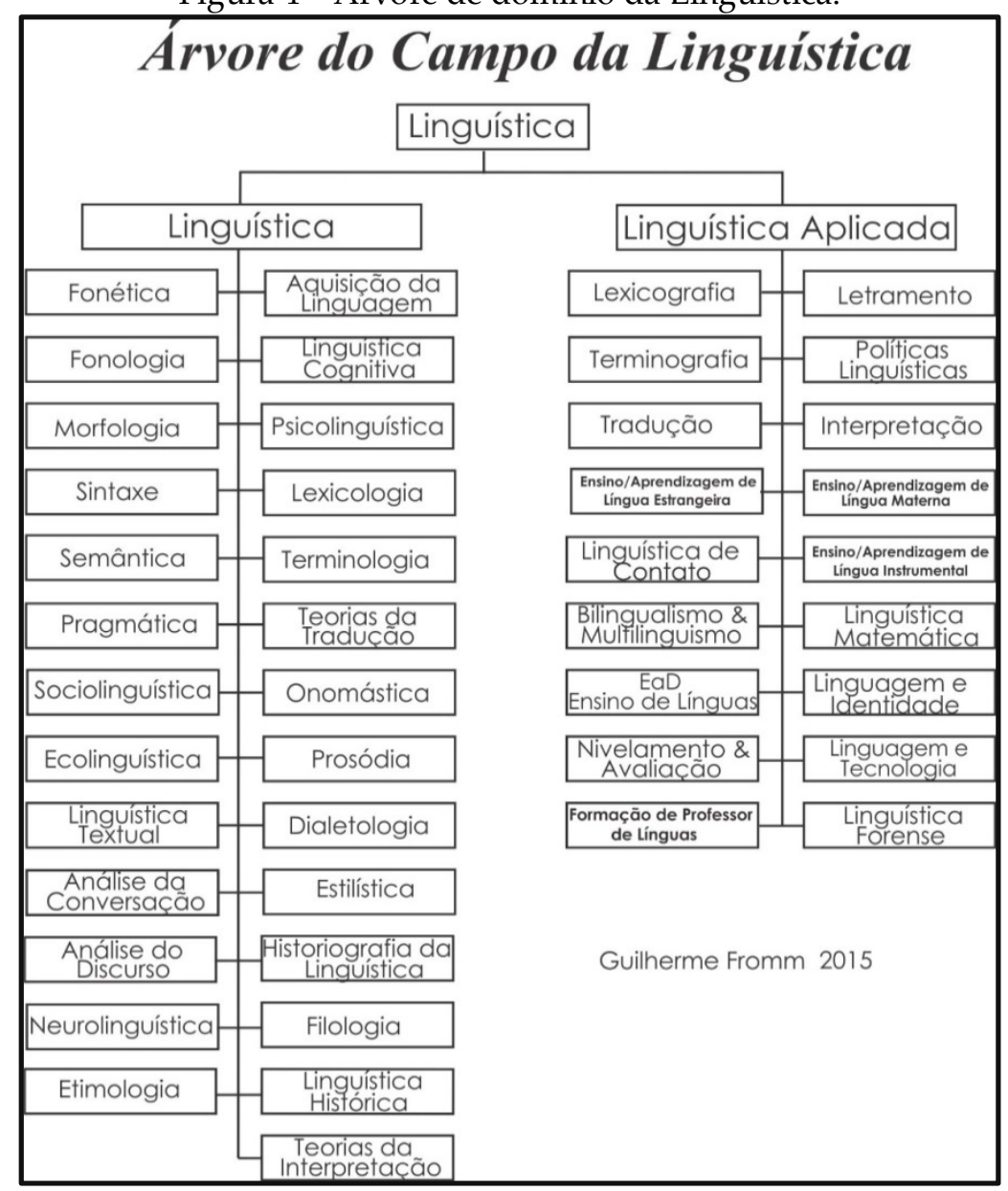

Fonte: Fromm (2015).

A árvore do campo da Linguística, apresentada na figura 4, foi constituída a partir de estudo de FROMM (2007). Segundo Fromm e Yamamoto (2013), essa árvore passou por um processo de revisão entre pares (especialistas). Os autores reconhecem que:

[...] foi gerada uma discussão em torno da árvore, pois muitos colegas não concordaram com a divisão da Linguística entre Linguística e Linguística Aplicada - a taxonomia da área não é clara nem para os 
especialistas; muitas subáreas da Linguística entraram e saíram da árvore várias vezes, conforme sugestões; outras subáreas, como Filologia, Linguística Histórica e Linguística Comparativa acabam por não ter sua delimitação de campo de pesquisa claramente identificada em textos dessas áreas (FROMM; YAMAMOTO, 2013, p. 4).

Porém, as áreas foram sendo divididas e subdivididas de acordo com o corpus compilado. O corpus para a composição da árvore da Linguística abrange todas as áreas mencionadas na proposta apresentada e foi analisado pelos autores dessa taxonomia.

Há várias questões que se relacionam no que diz respeito à Linguística Aplicada e à Lexicografia Pedagógica; restringimo-nos a apresentar algumas. De acordo com Leffa (2001):

A Linguística Aplicada é uma prestadora de serviços quando assessora, por exemplo, o professor na preparação de material de ensino de línguas, materna ou não, quando aprimora um instrumento de trabalho para o tradutor que precisa verter um texto de uma língua para outra; quando auxilia um profissional na maneira como ele deve tratar seu cliente para obter resultados mais satisfatórios (LEFFA, 2001, p. 5).

Conforme Welker (2011), assim como para a Lexicografia há a distinção entre o viés prático e teórico, para a Lexicografia Pedagógica (doravante LP) também há. A Lexicografia Pedagógica Teórica ou Metalexicografia Pedagógica abrange os subsídios teóricos que se referem aos dicionários pedagógicos. A Lexicografia Pedagógica Prática lida diretamente com a elaboração dos dicionários pedagógicos, que devem ser um material de apoio ao ensino de línguas mais aprimorado e refinado do que os dicionários comuns de língua. Desse modo, a LP se insere na LA justamente porque tem esse perfil prático de prestadora de serviços mencionado no excerto extraído de Leffa (2001).

Na LA, "a prestação de serviços não deve ser feita apenas a partir daquilo que se tem para oferecer, mas também a partir daquilo que a sociedade precisa" (LEFFA, 
2001, p. 6). Da mesma forma, a LP visa elaborar um produto (no caso, dicionários pedagógicos), que atenda às necessidades de um público-alvo, em consonância com o atributo de relevância social da LA. Os dicionários pedagógicos "pretendem levar em conta as habilidades (e, portanto, também as dificuldades) e as necessidades de consulta dos aprendizes de línguas" (WELKER, 2011, p. 105). Isso vai ao encontro dos tipos de problemas que são pesquisados em LA:

em Linguística Aplicada não criamos problema para pesquisar, mas pesquisamos os problemas que já existem. Não trazemos o problema para o laboratório, limpo e desinfetado, cuidadosamente desembaraçado de todas as variáveis que possam atrapalhar ou sujar nossas hipóteses. Fazemos o caminho inverso. Saímos do laboratório e vamos pesquisar o problema onde ele estiver: na sala de aula, na empresa ou na rua (LEFFA, 2001, p. 7).

Assim como a LA, a Lexicografia Pedagógica trabalha com problemas existentes. É por meio da identificação dos problemas presentes no uso de dicionários que é possível criar um produto que minimize as dificuldades dos consulentes. Conforme Duran e Xatara (2007) esclarecem, os dicionários pedagógicos devem ser testados pelo público-alvo e têm por objetivo eliminar dúvidas que um aprendiz de língua possa ter e equívocos que ele possa cometer. “Enquanto na Lexicografia tradicional muitas vezes se julga um dicionário pela quantidade de entradas, na LP quantidade não é sinônimo de qualidade. A qualidade está, antes, relacionada ao grau de satisfação que o aprendiz sente ao fazer o uso do dicionário" (DURAN; XATARA, 2007, p. 204).

De acordo com Duran e Xatara (2007), a LA ainda possui outro ponto em comum com a LP, que é "descobrir meios de tornar a aquisição do léxico mais efetiva" (DURAN; XATARA, 2007, p. 215), de modo que estudos da área de LA tratam da utilização de dicionários em pesquisas que visam vocabulário. Conforme as autoras, “pesquisas sobre a aquisição, retenção e recuperação do léxico são particularmente 
valiosas para a LP, pois podem subsidiar decisões sobre a melhor forma de exibir as informações nos dicionários" (DURAN; XATARA, 2007, p. 215).

Outra questão fundamental é que tanto a LA quanto a LP visam à língua em uso e, por isso, podemos relacioná-las à metodologia/abordagem da Linguística de Corpus, que também parte da língua em uso. Conforme Leffa (2001), o campo da Linguística Aplicada é “o estudo da língua em uso: a linguagem como acontece na sala de aula ou na empresa, falada por uma criança ou por uma pessoa de idade, expressando uma ideia ou uma emoção, etc." (LEFFA, 2001, p. 3). Segundo Biderman (2002), a LC é fundamental, visto que há uma tendência em se valorizar os dicionários que são elaborados com base em corpus, ou seja, que têm como base o uso real da língua: "na moderna Lexicografia, qualquer obra de vulto [...] deveria fundamentar-se em um corpus informatizado como fonte de referência na extração e seleção das entradas (lemas) do dicionário" (BIDERMAN, 2002, p. 92).

Antes de passarmos à seção metodológica deste artigo, consideramos válido mencionar que, consoante Krieger (2012), no Brasil, a análise de dicionários escolares é um importante foco quando pensamos em Lexicografia Pedagógica. "Assim, a Lexicografia Pedagógica postula que não há apenas um dicionário escolar, mas dicionários destinados à escola" (KRIEGER, 2012, p. 173). Nessa perspectiva, o Programa Nacional do Livro Didático (doravante PNLD), em 2012, adotou diretrizes que especificaram a quais públicos determinadas obras lexicográficas escolares devem ser destinadas. A seguir, no Quadro 1, expomos a última tipologia publicada, criada pelo PNLD, que direcionou a seleção de obras lexicográficas que foram entregues às escolas públicas: 
Quadro 1 - Tipologia PNLD 2012.

\begin{tabular}{|c|c|c|}
\hline $\begin{array}{c}\text { Tipos de } \\
\text { dicionários }\end{array}$ & Etapas de ensino & Caracterização \\
\hline $\begin{array}{l}\text { Dicionários de } \\
\text { Tipo } 1\end{array}$ & $\begin{array}{l}1^{\mathrm{o}} \text { ano do Ensino } \\
\text { Fundamental }\end{array}$ & $\begin{array}{l}\text { Mínimo de } 500 \text { e máximo de } \\
1.000 \text { verbetes; } \\
\text { Proposta } \\
\text { adequada às demandas do } \\
\text { processo de alfabetização } \\
\text { inicial. }\end{array}$ \\
\hline $\begin{array}{l}\text { Dicionários de } \\
\text { Tipo } 2\end{array}$ & $\begin{array}{l}2^{\mathrm{o}} \text { ao } 5^{\mathrm{o}} \text { ano do Ensino } \\
\text { Fundamental }\end{array}$ & $\begin{array}{l}\text { Mínimo de } 3.000 \text { e máximo de } \\
15.000 \text { verbetes; } \\
\text { Proposta lexicográfica } \\
\text { adequada a alunos em fase de } \\
\text { consolidação do domínio tanto } \\
\text { da escrita quanto da } \\
\text { organização e da linguagem } \\
\text { típicas do gênero dicionário. }\end{array}$ \\
\hline $\begin{array}{l}\text { Dicionários de } \\
\text { Tipo } 3\end{array}$ & $\begin{array}{l}6^{\mathrm{o}} \text { ao } 9^{\mathrm{o}} \text { ano do Ensino } \\
\text { Fundamental }\end{array}$ & $\begin{array}{l}\text { Mínimo de } 19.000 \text { e máximo de } \\
35.000 \text { verbetes; } \\
\text { Proposta lexicográfica } \\
\text { orientada pelas características } \\
\text { de um dicionário padrão de } \\
\text { uso escolar, porém adequada a } \\
\text { alunos dos últimos anos do } \\
\text { ensino fundamental. }\end{array}$ \\
\hline $\begin{array}{l}\text { Dicionários de } \\
\text { Tipo } 4\end{array}$ & $\begin{array}{l}1^{\underline{a}} \text { ao } 3^{\mathrm{o}} \text { ano do Ensino } \\
\text { Médio }\end{array}$ & $\begin{array}{l}\text { Mínimo de } 40.000 \text { e máximo de } \\
100.000 \text { verbetes; } \\
\text { Proposta lexicográfica própria } \\
\text { de um dicionário padrão, } \\
\text { porém adequada às demandas } \\
\text { escolares do ensino médio, } \\
\text { inclusive o profissionalizante. }\end{array}$ \\
\hline
\end{tabular}

Fonte: BRASIL, 2012, p. 19.

Na sequência, elaboramos o Quadro 2, que contém os títulos das obras que foram entregues às escolas públicas brasileiras de acordo com as tipologias: 
Quadro 2 - Dicionários destinados às escolas.

\begin{tabular}{|c|c|c|c|}
\hline Tipo 1 & Tipo 2 & Tipo 3 & Tipo 4 \\
\hline $\begin{array}{l}\text { 1. BECHARA, } \\
\text { Evanildo. Dicionário } \\
\text { infantil ilustrado } \\
\text { Evanildo Bechara. } \\
\text { Rio de Janeiro: } \\
\text { Nova Fronteira, } \\
\text { 2011. [1.000 } \\
\text { verbetes] }\end{array}$ & $\begin{array}{l}\text { 1. BIDERMAN, } \\
\text { Maria Tereza } \\
\text { Camargo. Dicionário } \\
\text { ilustrado de } \\
\text { português. } 2 \text { ed. São } \\
\text { Paulo: Ática, } 2009 . \\
\text { [5.900 verbetes] }\end{array}$ & $\begin{array}{l}\text { 1. BECHARA, } \\
\text { Evanildo (org.). } \\
\text { Dicionário escolar } \\
\text { da Academia } \\
\text { Brasileira de Letras. } \\
3 \text { ed. São Paulo: } \\
\text { Cia. Ed. Nacional, } \\
\text { 2011. } \\
\text { [28.805 verbetes] }\end{array}$ & $\begin{array}{l}\text { 1. BECHARA, } \\
\text { Evanildo. Dicionário } \\
\text { da língua } \\
\text { portuguesa Evanildo } \\
\text { Bechara. Rio de } \\
\text { Janeiro: Nova } \\
\text { Fronteira, } 2011 . \\
\text { [51.210 } \\
\text { entradas (verbetes e } \\
\text { locuções)] }\end{array}$ \\
\hline $\begin{array}{l}\text { 2. BIDERMAN, } \\
\text { Maria Tereza } \\
\text { Camargo; } \\
\text { CARVALHO, } \\
\text { Carmen Silvia. Meu } \\
\text { primeiro livro de } \\
\text { palavras; um } \\
\text { dicionário ilustrado } \\
\text { do português } \\
\text { de A a Z. } 3 \text { ed. São } \\
\text { Paulo: Ática, } 2011 . \\
\text { [999 verbetes] }\end{array}$ & $\begin{array}{l}\text { 2. BORBA, } \\
\text { Francisco S. } \\
\text { Palavrinha viva; } \\
\text { dicionário } \\
\text { ilustrado da língua } \\
\text { portuguesa. } \\
\text { Curitiba: Piá, } 2011 . \\
\text { [7.456 verbetes] }\end{array}$ & $\begin{array}{l}\text { 2. FERREIRA, } \\
\text { Aurélio Buarque de } \\
\text { Holanda. } \\
\text { Aurélio Júnior: } \\
\text { dicionário escolar } \\
\text { da } \\
\text { língua portuguesa. } \\
2 \text { ed. Curitiba: } \\
\text { Positivo, } \\
\text { 2011. [30.373 } \\
\text { verbetes] }\end{array}$ & $\begin{array}{l}\text { 2. BORBA, } \\
\text { Francisco S. } \\
\text { Dicionário Unesp do } \\
\text { português } \\
\text { contemporâneo. } \\
\text { Curitiba: } \\
\text { Piá, 2011. [58.237 } \\
\text { verbetes] }\end{array}$ \\
\hline \multirow[t]{2}{*}{$\begin{array}{l}\text { 3. GEIGER, Paulo } \\
\text { (org.). Meu primeiro } \\
\text { dicionário } \\
\text { Caldas Aulete com a } \\
\text { Turma do Cocoricó. } \\
2 \text { ed. São Paulo: } \\
\text { Globo, 2011. [1.000 } \\
\text { verbetes] }\end{array}$} & $\begin{array}{l}\text { 3. BRAGA, Rita de } \\
\text { Cássia Espechit; } \\
\text { MAGALHÃES, } \\
\text { Márcia A. } \\
\text { Fernandes. Fala } \\
\text { Brasil!; } \\
\text { dicionário ilustrado } \\
\text { da língua } \\
\text { portuguesa. } \\
\text { Belo Horizonte: } \\
\text { Dimensão, 2011. } \\
\text { [5.400 verbetes] }\end{array}$ & $\begin{array}{l}\text { 3. GEIGER, Paulo } \\
\text { (org.). Caldas Aulete } \\
\text { - minidicionário } \\
\text { contemporâneo da } \\
\text { língua } \\
\text { portuguesa. } 3 \text { ed. Rio } \\
\text { de Janeiro: Lexikon, } \\
\text { 2011. [29.431 } \\
\text { verbetes] }\end{array}$ & $\begin{array}{l}\text { 3. GEIGER, Paulo } \\
\text { (org.). Novíssimo } \\
\text { Aulete } \\
\text { dicionário } \\
\text { contemporâneo da } \\
\text { língua } \\
\text { portuguesa. Rio de } \\
\text { Janeiro: Lexikon, } \\
\text { 2011. [75.756 } \\
\text { verbetes] }\end{array}$ \\
\hline & $\begin{array}{l}\text { 4. FERREIRA, } \\
\text { Aurélio Buarque de } \\
\text { Holanda. } \\
\text { Dicionário Aurélio } \\
\text { ilustrado. Curitiba: } \\
\text { Positivo, } 2008 . \\
\text { [10.243 verbetes] }\end{array}$ & $\begin{array}{l}\text { 4. RAMOS, Rogério } \\
\text { de Araújo (ed. } \\
\text { resp.). } \\
\text { Dicionário didático de } \\
\text { língua portuguesa. } \\
2 \text { ed. São Paulo: SM, } \\
2011 . \\
\text { [26.117 verbetes] }\end{array}$ & $\begin{array}{l}\text { 4. HOUAISS, } \\
\text { Antônio (org.); } \\
\text { VILLAR, Mauro } \\
\text { de Salles (ed. resp.). } \\
\text { Dicionário Houaiss } \\
\text { conciso. São Paulo: } \\
\text { Moderna, 2011. } \\
\text { [41.243 verbetes] }\end{array}$ \\
\hline
\end{tabular}




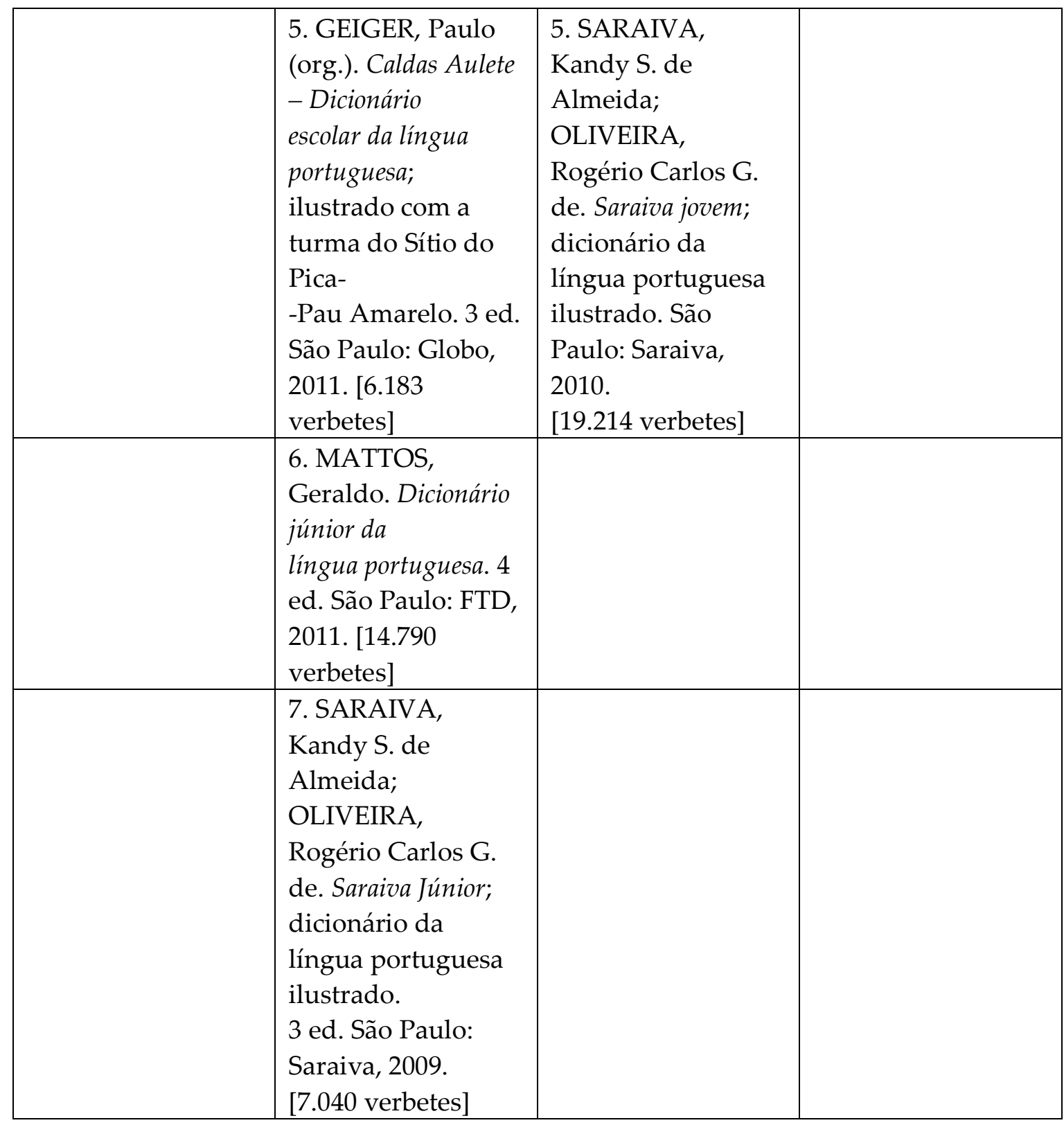

Fonte: BRASIL, 2012, p. 23-35.

Conforme Krieger (2006), a criação das tipologias foi muito importante, porque sinalizou a relevância da LP no cenário nacional. No entanto, tendo em vista que a LP é uma área ainda muito recente no Brasil, é válido analisar, conforme Welker (2008), os dicionários escolares a fim de perceber se eles são realmente pedagógicos. $\mathrm{Na}$ sequência, apresentamos a seção metodológica deste artigo. 


\section{Metodologia}

Para respondermos às perguntas lançadas na introdução do presente artigo, compilamos um corpus constituído por artigos científicos que dizem respeito à Lexicografia Pedagógica, uma vez que textos desta subárea, em específico, não compõem o Corpus de Linguística Aplicada, ao qual tivemos acesso. Portanto, nesta seção, apresentamos o passo a passo para a elaboração do Corpus de Lexicografia Pedagógica e o trabalho que efetuamos com tal corpus por meio do programa de análise lexical WordSmith Tools (doravante WST).

\subsection{Elaboração do Corpus de Lexicografia Pedagógica}

Para elaboração do Corpus de Lexicografia Pedagógica, buscamos no Google pelos termos "Lexicografia Pedagógica" e "Metalexicografia Pedagógica". Restringimos a nossa busca na medida em que compilamos apenas artigos científicos no formato pdf. que realmente abordavam questões da LP. Além disso, para cada termo de busca, ativemo-nos a analisar apenas as três primeiras páginas de resultados até baixarmos 20 textos - número que consideramos suficiente para o recorte deste trabalho. Em seguida, salvamos todos os textos no formato TXT. (bloco de notas), com a codificação Unicode e inserimos cabeçalho com data e local de acesso. O Corpus de Lexicografia Pedagógica possui 10.869 formas distintas (palavras sem repetições) e 113.286 formas corridas (palavras com repetições).

Na sequência, descrevemos como trabalhamos com o Corpus de Lexicografia Pedagógica no WST, a fim de que chegássemos à identificação de características atribuídas ao termo "dicionário(s) pedagógico(s)". 


\subsection{WordSmith Tools: processo para identificar características atribuídas a "dicionário(s) pedagógico(s)"}

Carregamos o Corpus de Lexicografia Pedagógica no WST versão 6.0 e fizemos a WordList, conforme ilustra a Figura 5:

Figura 5 - WordList do Corpus LP.

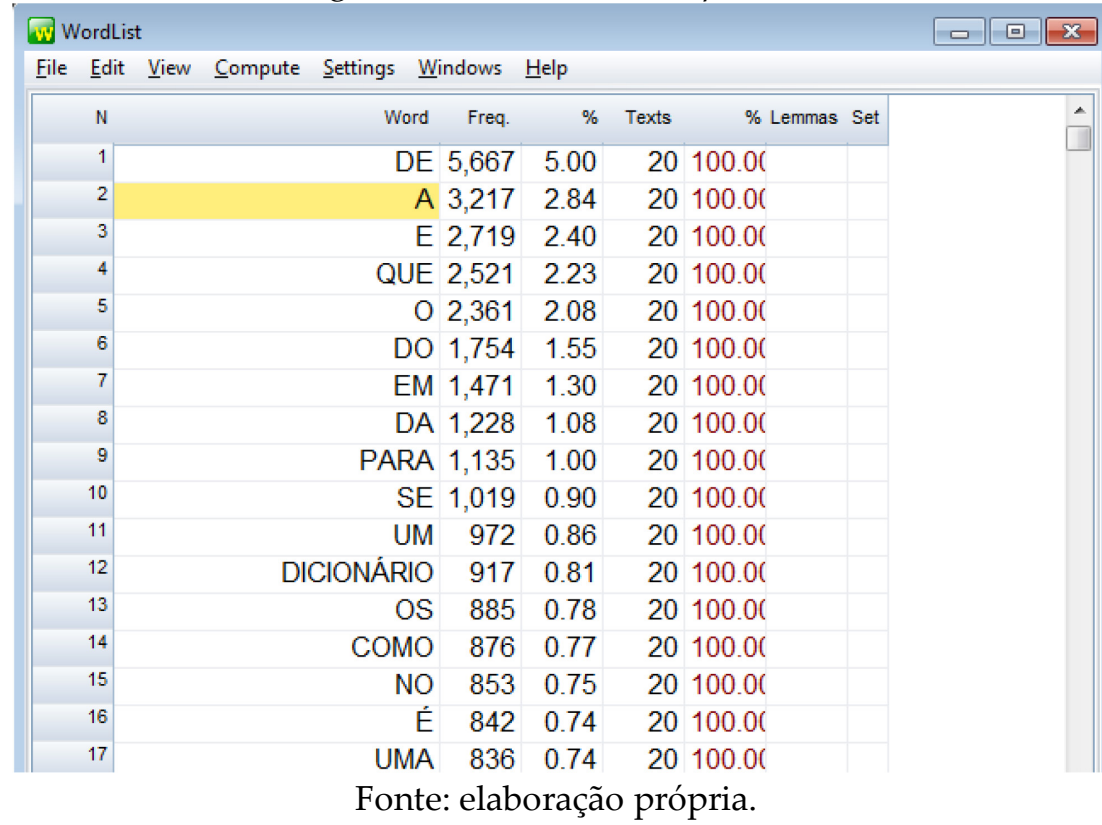

Em seguida, localizamos as palavras "pedagógico" e "pedagógicos" e clicamos em concordance, para o programa gerar as linhas de concordância dessas palavras. Depois, fomos à aba collocates, que nos apresentou as palavras usadas ao lado de "pedagógico" e ao lado de "pedagógicos", conforme ilustram as Figuras 6 e 7. 
Figura 6 - Colocado com "pedagógico".

\begin{tabular}{|c|c|c|c|c|c|c|c|c|c|}
\hline \multicolumn{10}{|c|}{ Concord } \\
\hline File & $\underline{\underline{E} \text { dit }}$ & View Compute & Settings Window & vs $\underline{\text { Help }}$ & & & & & \\
\hline \multicolumn{2}{|r|}{$\mathrm{N}$} & Word & With & Relation & Set & Texts & Total & Total & Total \\
\hline & 1 & PEDAGÓGICO & pedagógico & 0.000 & & 16 & 63 & 0 & 0 \\
\hline & 2 & DE & pedagógico & 0.000 & & 13 & 36 & 21 & 15 \\
\hline & 3 & 0 & pedagógico & 0.000 & & 13 & 29 & 23 & 6 \\
\hline & 4 & DICIONÁRIO & pedagógico & 0.000 & & 8 & 20 & 17 & 3 \\
\hline & 5 & UM & 1 pedagógico & 0.000 & & 9 & 17 & 12 & 5 \\
\hline & 6 & QUE & pedagógico & 0.000 & & 8 & 16 & 7 & 9 \\
\hline & 7 & NO & pedagógico & 0.000 & & 7 & 15 & 10 & 5 \\
\hline & 8 & A & pedagógico & 0.000 & & 8 & 13 & 3 & 10 \\
\hline & 9 & $\mathrm{E}$ & pedagógico & 0.000 & & 10 & 13 & 7 & 6 \\
\hline & 10 & OBRAS & pedagógico & 0.000 & & 7 & 10 & 8 & 2 \\
\hline & 11 & LEXICOGRÁFIC & ( pedagógico & 0.000 & & 4 & 10 & 10 & 0 \\
\hline
\end{tabular}

Fonte: elaboração própria.

Figura 7 - Colocado com "pedagógicos".

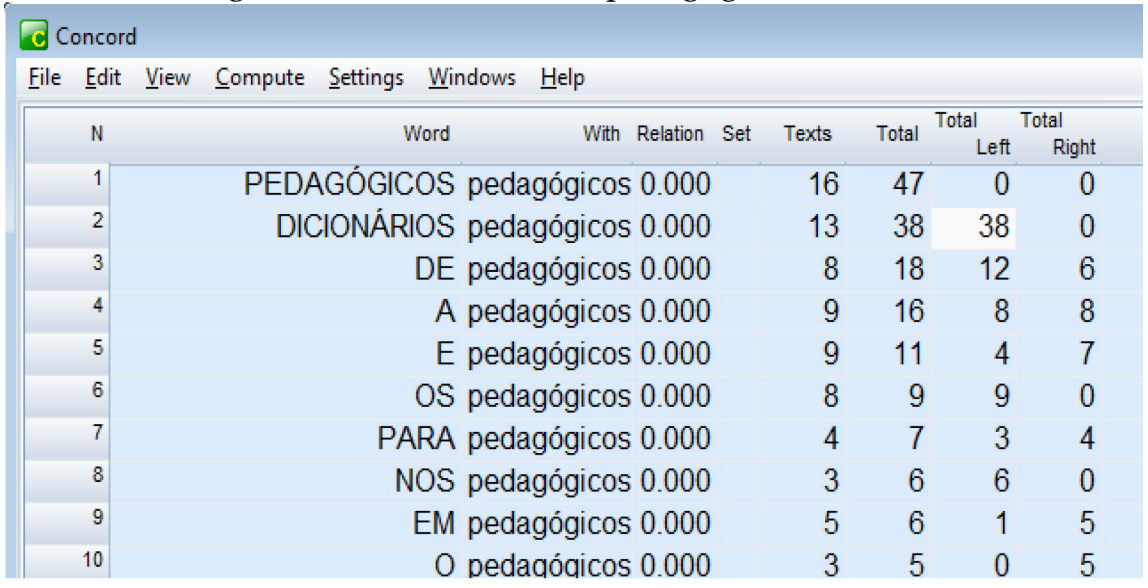

Fonte: Elaboração própria.

Como podemos ver nas Figuras 6 e 7, a palavra "dicionário" à esquerda de "pedagógico" ocorreu 17 vezes e a palavra "dicionários" à esquerda de "pedagógicos" ocorreu 38 vezes. Dessa forma, clicamos nesses resultados para termos acesso às linhas de concordância em que houve ocorrências referentes a "dicionário pedagógico" e a "dicionários pedagógicos", conforme ilustram as Figuras 8 e 9. 
Figura 8 - Linhas de concordância de "dicionário pedagógico".

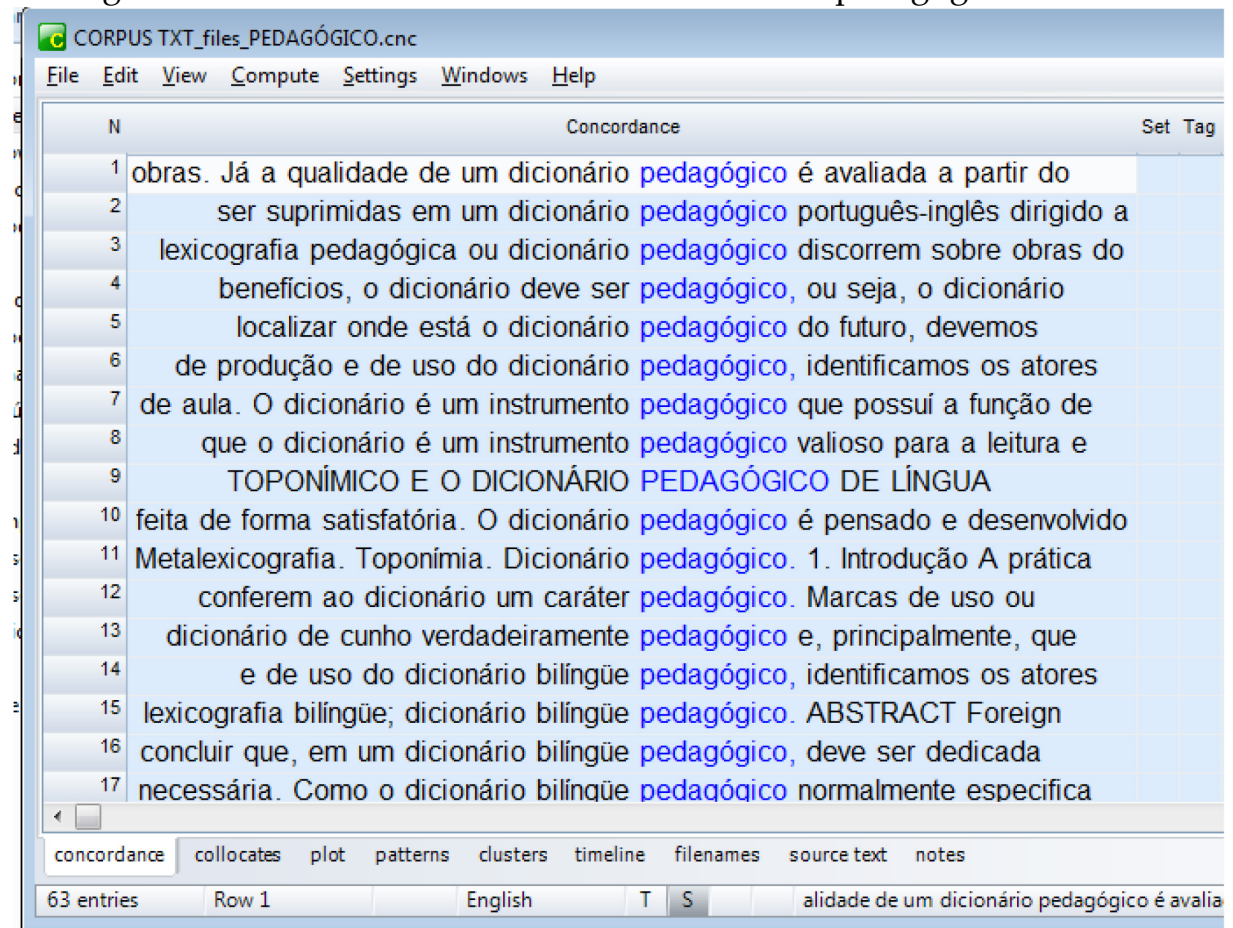

Fonte: elaboração própria.

Figura 9 - Linhas de concordância de "dicionários pedagógicos".

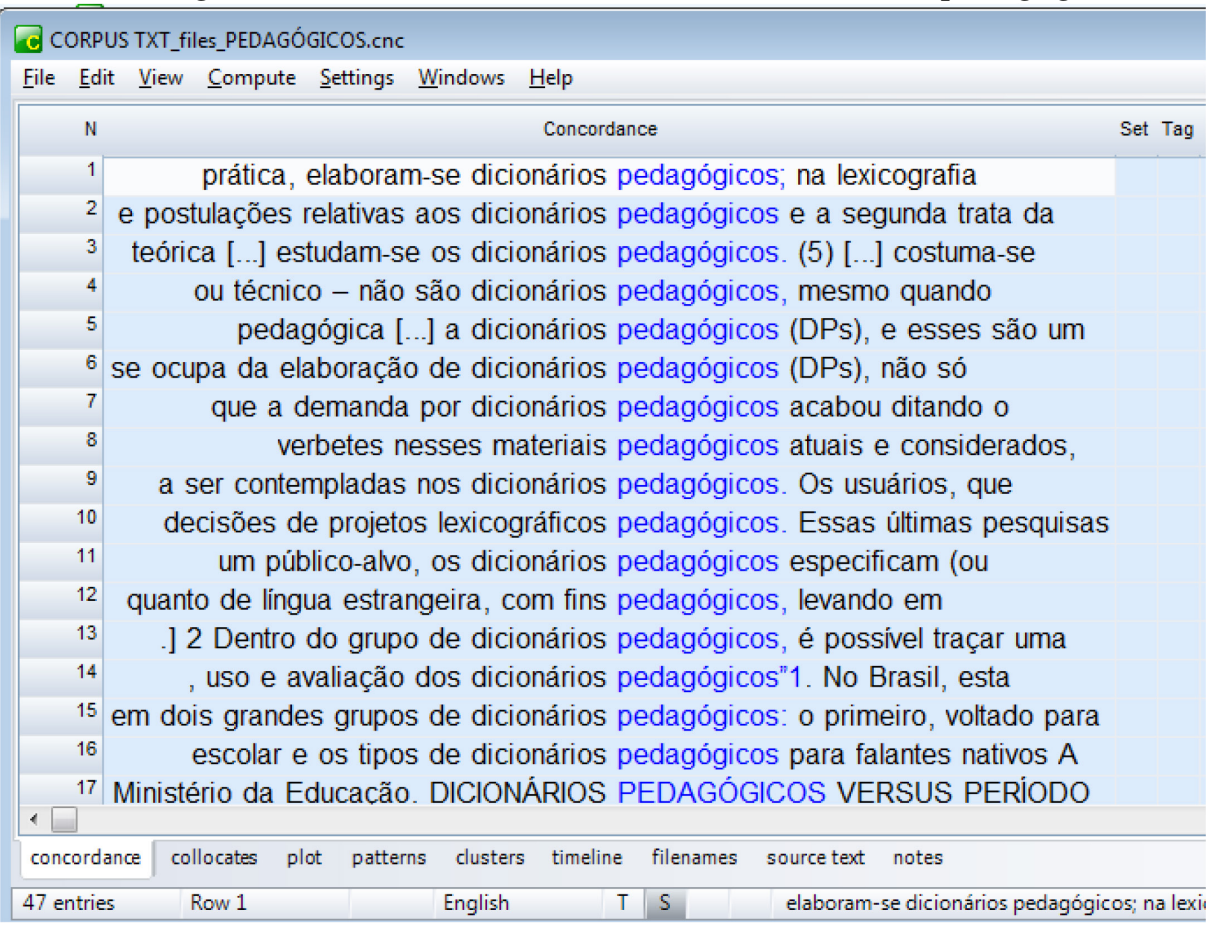

Fonte: elaboração própria.

A partir disso, lemos os contextos linguísticos das linhas de concordância em questão para encontrarmos quais características foram atribuídas a "dicionário(s) 
pedagógico(s)" . Tais características tornaram-se base para a análise que efetuamos referente à proposta lexicográfica dos dicionários escolares Houaiss Conciso e Novíssimo Aulete.

\section{Análises e resultados}

Nesta seção, apresentamos as análises e resultados aos quais chegamos a partir da metodologia descrita na seção anterior. Analisamos, em específico, as linhas de concordância referentes ao termo "dicionário(s) pedagógico(s)" e a proposta lexicográfica dos dicionários Houaiss Conciso e Novíssimo Aulete.

\subsection{Corpus de Lexicografia Pedagógica: características atribuídas ao termo "dicionário(s) pedagógico(s)"}

No que diz respeito à análise das 17 linhas de concordância referentes a "dicionário pedagógico" (no singular), selecionamos 7 linhas de concordância que, para nós, apresentam características a respeito de um dicionário pedagógico:

Linha 1: Já a qualidade de um dicionário pedagógico é avaliada a partir do julgamento de sua adequação às necessidades dos usuários: nesse tipo de dicionário nem sempre mais significa melhor.

Linha 2: No entanto, para que o aluno obtenha maiores benefícios, o dicionário deve ser pedagógico, ou seja, o dicionário deve ser planejado e estruturado levando em consideração os objetivos específicos e o público-alvo.

Linha 3: O dicionário pedagógico é pensado e desenvolvido para um público-alvo e objetivo específico, e por este motivo o professor dever estar atento às necessidades do aluno, considerando seu nível escolar.

Linha 4: Como as necessidades dos aprendizes variam em relação a cada unidade lexical, é exatamente ao ajustar o conteúdo dos verbetes às necessidades de um determinado público de aprendizes que os profissionais envolvidos em um projeto 
lexicográfico conferem ao dicionário um caráter pedagógico.

Linha 5: Não só no Brasil, a falta de iniciativa editorial para geração e dicionários costuma ser suprida por iniciativas acadêmicas e os caminhos para isso são os tradicionais: escolha de uma nomenclatura a partir da frequência em um corpus de língua, reaproveitamento de definições de dicionários monolíngues, seleção e adaptação de exemplos com base em corpus de língua. Contudo, isso não garante que o resultado seja um dicionário de cunho verdadeiramente pedagógico e, principalmente, que reflita as necessidades do público-alvo.

Linha 6: Dessa forma, pode-se concluir que, em um dicionário bilíngue pedagógico, deve ser dedicada atenção especial aos exemplos, a fim de que contenham informações relevantes sobre a entrada. $\mathrm{O}$ reaproveitamento de exemplos de outros dicionários deveria ser evitado e os corpora deveriam ser utilizados apenas como base e não como autoridade final para a composição dos exemplos.

Linha 7: Como o dicionário bilíngue pedagógico normalmente especifica seu públicoalvo, dirigindo-se a falantes nativos de apenas uma das línguas envolvidas, fica mais fácil decidir que notas incluir.

No que tange à análise das 38 linhas de concordância referentes a "dicionários pedagógicos" (no plural), selecionamos 11 linhas de concordância que, para nós, também apresentam características a respeito de um dicionário pedagógico:

Linha 1: Dessa forma, as dificuldades típicas de cada nacionalidade em relação ao léxico de uma língua estrangeira começaram a ser contempladas nos dicionários pedagógicos.

Linha 2: Além de especificarem um público-alvo, os dicionários pedagógicos especificam (ou deveriam) o tipo de função que se propõem a apoiar. Isso porque não basta perguntar se uma informação é relevante para um determinado público-alvo, mas também em que situação essa informação é relevante.

Linha 3: Não obstante essa abrangência, especificamente, a Lexicografia Pedagógica costuma: [...] restringir-se a dicionários pedagógicos (DPs), e esses são um tipo especial de obras de referência. Sua característica é que eles pretendem levar em conta as habilidades (e, portanto, também as dificuldades) e as necessidades de consulta dos 
aprendizes de língua. (WELKER, 2011, p. 105)

Linha 4: Durante a atividade de correção de redações ou durante a produção oral dos alunos, o professor tem contato com erros típicos dos aprendizes brasileiros, dificuldades que podem ser o ponto de partida para a elaboração de soluções nos dicionários pedagógicos.

Linha 5: O desenvolvimento da Lexicografia Pedagógica, em nível mundial, trouxenos relatos de experiências bem sucedidas, em especial a utilização do corpus de aprendizes como recurso para identificação de dificuldades que deveriam ser supridas pelos dicionários pedagógicos.

Linha 6: Várias decisões são tomadas pelo lexicógrafo para planejar a elaboração de um dicionário e todas elas têm que levar em conta o usuário a que se destina a obra (no caso dos dicionários pedagógicos, o aprendiz).

Linha 7: Essa tendência também foi relatada por Rundell (1999), o qual argumenta que, nos dicionários pedagógicos, não é desejável apresentar registros raros de uso da língua, mas sim focar o que é comum, típico e frequente.

Linha 8: Hoje quase não se discute mais o uso de um vocabulário controlado para a metalinguagem nos dicionários pedagógicos: ele é praticamente uma característica obrigatória deles.

Linha 9: No entanto, os estudos de frequência das línguas produziram o chamado "vocabulário fundamental" de cada uma delas, ou seja, o conjunto de lexemas que compõem o vocabulário ativo (utilizado para falar e escrever) de um falante nativo prototípico. Esse vocabulário precisa, com toda certeza, ser contemplado nos dicionários pedagógicos.

Linha 10: Contudo, acreditamos que a contribuição da Linguística de Corpus para a Lexicografia não se restringe ao levantamento de conteúdo para dicionários. Os corpora de aprendizes representam uma fonte de dados para pesquisas que visem conhecer o perfil e a necessidade do público-alvo dos dicionários pedagógicos (v. Granger 2004).

Linha 11: Para produzir um discurso mais natural e próximo daquele de um falante nativo, é preciso que o aprendiz estrangeiro disponha de informações que indiquem, por exemplo, se determinado uso da unidade lexical é literário, figurado ou coloquial (marcas diafásicas); se é um regionalismo (marcas diatópicas); se é familiar, popular, gíria ou linguagem de baixo calão (marcas diastráticas). Além de incluir esse tipo de 
informação, os dicionários pedagógicos deveriam explicitá-lo sem o uso de marcas ou abreviaturas, ou seja, por extenso.

A partir das referidas linhas de concordância, chegamos às principais características atribuídas a um dicionário pedagógico:

$\checkmark$ Especifica o público-alvo (o aprendiz);

$\checkmark$ Especifica o tipo de função a que se propõe apoiar (em que situação a informação contida no dicionário é relevante para o consulente)

$\checkmark$ É adequado às necessidades, às habilidades e aos objetivos específicos do público-alvo;

$\checkmark$ Possui exemplos que não devem ser reaproveitados de outros dicionários;

$\checkmark$ Leva em consideração a utilização de um corpus de aprendizes para produção do dicionário pedagógico, a fim de identificar as dificuldades deles;

$\checkmark$ É feito a partir de um corpus de língua que não pode ser utilizado como autoridade final para elaboração de exemplos;

$\checkmark$ Contém registros frequentes (vocabulário fundamental ou ativo);

Adota um vocabulário controlado para a metalinguagem;

$\checkmark$ Indica por extenso as marcas de uso de uma unidade lexical.

Tratamos tais características como critérios a serem analisados, a seguir, na proposta lexicográfica dos dicionários escolares Houaiss Conciso e Novíssimo Aulete.

\subsection{Análise dos dicionários Houaiss Conciso e Novíssimo Aulete}

A partir da leitura da proposta lexicográfica dos dicionários Houaiss Conciso e Novíssimo Aulete, observamos se tais obras consideram alguma das características que um dicionário deve ter para ser pedagógico de acordo com o nosso Corpus de Lexicografia Pedagógica.

Em relação ao dicionário Houaiss Conciso, identificamos a especificação do público-alvo a que se destina: 
O texto concentrou-se nas demandas escolares do público-alvo deste dicionário do Tipo 4, aos alunos do $1^{\mathrm{o}}$ ao $3^{\mathrm{o}}$ ano do ensino médio, inclusive o profissionalizante - embora não apenas naquelas, por, enfim, se tratar de obra de utilidade geral (HOUAISS, 2011, p. vii).

Embora tenhamos encontrado a especificação do público-alvo, consideramos desapropriado o fato de estar explícita a informação de que foram utilizadas como base não apenas as demandas escolares dos alunos de $1^{\circ}$ ao $3^{\circ}$ ano do ensino médio, mas outras, que não sabemos de onde provêm, para a elaboração da obra. Para nós, isso camufla a ausência de informações mais específicas sobre as supostas demandas do público-alvo, o que corrobora a ideia de que não é possível afirmar com segurança que o Houaiss Conciso é pedagógico, conforme Grama (2016).

A afirmação de que a proposta lexicográfica foi elaborada a partir de "demandas escolares" significa que, na teoria, o dicionário teria sido elaborado a partir das necessidades, dificuldades, habilidades e objetivos específicos dos consulentes. No entanto, em nenhum momento, é mencionado que um corpus de aprendizes ou mesmo um corpus foi utilizado como base para a elaboração do dicionário Houaiss Conciso para verificar quais são as dificuldades e necessidades de aprendizagem do público-alvo. A única menção encontrada sobre a fonte das informações que constam na obra é a seguinte:

O levantamento da nomenclatura empregada e das informações que prestamos no corpo do dicionário linguístico e da enciclopédia teve em conta publicações utilizadas como obras de base em prestigiosas instituições de ensino brasileiras, estaduais e federais, para que as informações fornecidas fossem de máxima eficácia pedagógica (HOUAISS, 2011, p. vii).

Acreditamos que o referido excerto desconstrói a ideia de que o dicionário foi elaborado a partir das necessidades do público-alvo, uma vez que a seleção da macroestrutura e demais informações tiveram como base outras obras e publicações não especificadas. A partir disso, podemos inferir que os exemplos da microestrutura 
podem advir destas obras e publicações "prestigiadas" que são vistas como autoridade máxima.

Também não encontramos em que situação as informações contidas no dicionário são relevantes para o público-alvo. A afirmação de que a obra é de "utilidade geral" nos faz acreditar que especificar as situações de uso não foi uma prioridade.

Uma vez que não há menção sobre uso de corpus para elaboração da obra, não é possível saber se ela contém os registros (palavras-entrada) mais frequentes. No que alude à indicação das marcas de uso, estas estão presentes e são abreviadas, por exemplo: "pi.ra.do adj. B gír. Louco [ETIM: part. de pirar]” (HOUAISS, 2011, p. viii). Sobre o vocabulário controlado, não é possível fazer uma constatação sem analisar os verbetes, portanto não abordaremos essa questão nos dicionários analisados.

Na proposta lexicográfica do Novíssimo Aulete, há menção ao público-alvo a que se destina: "além de ter como escopo ser uma ferramenta útil ao estudante do ensino médio e pré-universitário na sua ampla diversidade, a obra visa também um universoalvo de universitários e de profissionais, sem esquecer o público em geral" (AULETE, 2011). Da mesma forma que o Houaiss Conciso, o Novíssimo Aulete não restringe seu público-alvo aos alunos de $1^{\mathrm{o}}$ a $3^{\mathrm{o}}$ ano do Ensino Médio.

Sobre em que situação o uso do dicionário é relevante para o consulente, não encontramos especificação.

Consideramos importante o trecho que diz:

Sua nominata de cerca de 75.000 vocábulos-verbetes origina-se do módulo principal do mesmo banco de dados que alimenta o idicionário Aulete. Este é uma edição digital, atualizada e ampliada, gratuita, na internet (www.aulete.com.br) do famoso e tradicional Dicionário Contemporâneo da Língua Portuguesa Caldas Aulete, cuja primeira edição portuguesa data de 1894 (AULETE, 2011). 
Fica evidente que a obra utiliza como base o mesmo banco de dados da versão digital thesaurus do Aulete. Isso significa que as informações contidas no Novíssimo Aulete não se baseiam em corpora exclusivamente de aprendizes. Dessa forma, a obra não leva em consideração as necessidades e as dificuldades do público-alvo, que deveria ser apenas os alunos do Ensino Médio. O excerto a seguir corrobora tal constatação, uma vez que nele se discorre mais sobre os corpora, mas não se especifica sua tipologia:

A busca de representatividade lexical seguiu parâmetros lexicográficos, a começar pela frequência de uso, registrada em corpora da língua portuguesa - grandes arquivos de textos da língua efetivamente em uso, levando-se em consideração tanto usos comuns como científicos e tecnológicos de modo a contemplar o léxico geral e o especializado. Além disso, os corpora também foram fonte de novos significados acrescidos aos vocábulos já existentes na língua (AULETE, 2011).

A partir do trecho acima, confirmamos que as entradas foram selecionadas a partir do critério de frequência, o que é positivo. No que diz respeito aos exemplos, estes estão presentes, mas têm como fonte o mesmo banco de dados da obra na versão digital e thesaurus, o que quer dizer que os exemplos são reaproveitados de uma obra que não é pedagógica, conforme Grama (2016) já havia constatado. Vale ressaltar que a obra não lança mão apenas de exemplos extraídos dos corpora, mas de abonações literárias, jornalísticas e de letras de música popular. Diante disso, questionamos: qual é o critério para decidir quando usar um exemplo ou uma abonação nos verbetes? Isso não é explicado, mas deveria ser levado em consideração, uma vez que o consulente é um aprendiz.

Na proposta lexicográfica, encontramos esclarecimentos sobre as marcas de uso, que são chamadas de "indicação de contexto" e divididas em: "regionalismo", (informação sobre se determinada palavra é usada em um lugar no Brasil ou em outro país colonizado por Portugal), "nível de uso da língua", (informação sobre se 
determinada palavra é usada em âmbito familiar, por exemplo), e "rubrica", (informação sobre se a acepção de uma palavra pertence a uma área científica).

Para melhor visualização dos resultados da análise realizada, expomos o Quadro 3:

Quadro 3 - Resultados da análise efetuada sobre Houaiss Conciso e Novíssimo Aulete.

\begin{tabular}{|l|l|l|}
\hline Características & Houaiss Conciso & Novíssimo Aulete \\
\hline $\begin{array}{l}\text { 1) Especifica o público-alvo } \\
\text { obspecifica a situação de uso da } \\
\text { obra }\end{array}$ & Não & Sim \\
\hline $\begin{array}{l}\text { 3) Adequa-se às necessidades e Não } \\
\text { dificuldades do público-alvo }\end{array}$ & Não \\
\hline $\begin{array}{l}\text { 4) Contém exemplos não } \\
\text { reaproveitados de outros } \\
\text { dicionários }\end{array}$ & Não \\
\hline $\begin{array}{l}\text { 5) É elaborado a partir de um } \\
\text { corpus de aprendizes }\end{array}$ & Não & Não \\
\hline $\begin{array}{l}\text { 6) Contém os registros mais } \\
\text { frequentes Não }\end{array}$ & Sim \\
\hline 7) Indica as marcas de uso & Sim & Sim \\
\hline
\end{tabular}

Fonte: elaboração própria.

Conforme o Quadro 3, das sete características, o Novíssimo Aulete possui três, e o Houaiss Conciso apresenta apenas duas. A partir dos resultados expostos, podemos dizer que esses dicionários escolares entregues ao público do Ensino Médio no Brasil ainda não apresentam características suficientes que nos permitam afirmar que são dicionários pedagógicos. Inclusive, eles não atendem à principal característica que distingue um dicionário comum de um dicionário pedagógico, que é o atendimento às necessidades e dificuldades do público-alvo, já que não utilizaram como base um corpus de aprendizes nem efetuaram uma pesquisa com o público-alvo. 


\section{Considerações finais}

Em virtude do exposto, podemos responder às questões lançadas na introdução deste artigo. As características atribuídas ao termo “dicionário(s) pedagógico(s)" quando usamos a metodologia/abordagem da Linguística de Corpus se resumem aos seguintes itens:

$\checkmark$ Especifica o público-alvo (o aprendiz);

$\checkmark$ Especifica o tipo de função a que se propõe apoiar (em que situação a informação contida no dicionário é relevante para o consulente)

$\checkmark$ É adequado às necessidades, às habilidades e aos objetivos específicos do público-alvo;

$\checkmark$ Possui exemplos que não devem ser reaproveitados de outros dicionários;

$\checkmark$ Leva em consideração a utilização de um corpus de aprendizes para produção do dicionário pedagógico, a fim de identificar as dificuldades deles;

$\checkmark$ É feito a partir de um corpus de língua que não pode ser utilizado como autoridade final para elaboração de exemplos;

$\checkmark$ Contém registros frequentes (vocabulário fundamental ou ativo);

$\checkmark$ Adota um vocabulário controlado para a metalinguagem;

$\checkmark$ Indica por extenso as marcas de uso de uma unidade lexical.

Vimos que, na verdade, a maioria das características atribuídas ao termo “dicionário(s) pedagógico(s)" não foram mencionadas ou descritas na proposta lexicográfica dos dicionários escolares Tipo 4 Houaiss Conciso e Novíssimo Aulete. Isso nos indica que mais pesquisas que levem em conta a perspectiva da Linguística Aplicada em união com a Lexicografia Pedagógica devam ser desenvolvidas a fim de que as dificuldades, habilidades e objetivos dos públicos-alvo dos dicionários escolares sejam descobertos, para que seja possível elaborar obras que, de fato, sejam pedagógicas, ou seja, que realmente possam solucionar os problemas que existem ao 
se lançar mão de uma obra de consulta como o dicionário. Nessa perspectiva, podemos dizer que é preciso investir na construção de corpora de aprendizes que possam servir de base para a elaboração de dicionários pedagógicos.

É muito importante que haja pesquisas acadêmicas e obras que contribuam efetivamente para a minimização de um problema com relevância social, a saber, aquele que envolva o uso de linguagem, por exemplo, a ampliação lexical, o uso do vocabulário ativo, a adequação de uso de elementos de coesão em redações etc. Para isso, é preciso que não se perca de vista a importância da Linguística de Corpus, que propicia a utilização de corpus, com vistas ao uso real e efetivo da língua, tanto para descobrir as necessidades do público-alvo quanto para, a partir daí, elaborar uma obra pedagógica.

\section{Referências Bibliográficas}

AULETE, F. J. C.; GEIGER, P. (org.). Novíssimo Aulete dicionário contemporâneo da língua portuguesa. Rio de Janeiro: Lexikon, 2011.

BIDERMANN, M. T. C. Análise de dois dicionários gerais do português brasileiro contemporâneo: o Aurélio e o Houaiss. Filologia e Linguística Portuguesa, n. 5. São Paulo: USP, p. 85-116, 2002.

BRASIL. Ministério da Educação. Secretaria de Educação Básica. Programa Nacional do Livro Didático - Dicionários. Com direito à palavra: dicionários em sala de aula. Brasília: Ministério da Educação, Secretaria de Educação Básica, 2012.

BRITO, C. C. de P. LA: Panorama Histórico. In: Bases Teóricas em Linguística Aplicada (Disciplina). PPGEL/UFU, Uberlândia, 2017, Slides. (Material utilizado em aula).

CAVALCANTI, M. C. A propósito de Linguística Aplicada. Trabalhos em Linguística Aplicada, vol. 07, 1986. p. 05-12.

DURAN, M. S.; XATARA, C. M. Lexicografia Pedagógica: Atores e Interfaces. Delta. v. 23. n. 2. São Paulo: PUC, p. 203-222, 2007. Disponível em: 
https://revistas.pucsp.br/index.php/delta/article/view/30294/20948. Acesso em: 13 dez. 2017.

FROMM, G. Votec: a construção de vocabulários eletrônicos para aprendizes de tradução. 2007. 210 f. Tese (Doutorado em Letras) - Faculdade de Filosofia, Letras e Ciências Humanas, Universidade de São Paulo, São Paulo, 2007.

FROMM. Votec - Vocabulário Técnico Online. Ambiente Virtual Terminográfico Online, 2007. Disponível em: http://pos.votec.ileel.ufu.br. Acesso em: 04 dez. 2017.

FROMM. Árvore do Campo da Linguística, 2015.

FROMM, G.; YAMAMOTO, M. I. Terminologia, Terminografia, Tradução e Linguística de Corpus: a criação de um vocabulário bilíngue sobre Linguística. In: TAGNIN, S.; BEVILACQUA, C. Corpora na Terminologia. São Paulo: Hub Editorial, 2013.

GRAMA, D. F. Uma análise lexicográfica dos elementos coesivos sequenciais do português para a elaboração de uma proposta de definição: um estudo com base em corpus. 2016. 371 f. Dissertação (Mestrado em Estudos Linguísticos) - Instituto de Letras e Linguística, Universidade Federal de Uberlândia, Uberlândia, 2016.

HOUAISS, A. (Org.); VILLAR, M. S. (Ed.). Dicionário Houaiss conciso. São Paulo: Moderna, 2011.

KRIEGER, M. G. Políticas públicas e dicionários para escola: o programa nacional do livro didático e seu impacto sobre a lexicografia didática. Cadernos de Tradução, Florianópolis, Brasil. v.2, n.18, 2006, p. 235-252. Disponível em: https://periodicos.ufsc.br/index.php/traducao/article/view/6950/6458. Acesso em: 6 abr. 2015.

KRIEGER, M. G. Questões de lexicografia pedagógica. In: XATARA, Claudia; BELIVACQUA, Cleci Regina; HUMBLÉ, Philippe René Marie (org.). Dicionários na teoria e na prática: como e para quem são feitos. São Paulo: Parábola Editorial, 2011. p. 103-113. (Série: Estratégias de Ensino; 24)

KRIEGER, M. G. Dicionários escolares e ensino de língua materna. Estudos Linguísticos. v. 41. n. 1. São Paulo: USP, p. 169-180, jan-abr 2012. Disponível em: http://www.gel.org.br/estudoslinguisticos/volumes/41/el.2012 v1 t13 1.pdf. Acesso em: 13 dez. 2017. 
LEFFA, V. J. A linguística aplicada e seu compromisso com a sociedade. Trabalho apresentado no VI Congresso Brasileiro de Linguística Aplicada. Belo Horizonte: UFMG, 7-11 de outubro de 2001.

MOITA LOPES, L. P. Afinal, o que é Linguística Aplicada? In: MOITA LOPES, L. P. . Oficina de Linguística Aplicada: A Natureza Social e Educacional dos Processos de Ensino/Aprendizagem de Línguas. Campinas: Mercado de Letras, 1996. p. 17-25.

ROJO, R. H. R. Fazer linguística aplicada em perspectiva sócio-histórica: privação sofrida e leveza de pensamento. In: MOITA LOPES, L. P. (Org.). Por uma linguística aplicada INdisciplinar. São Paulo: Parábola Editorial, 2006. p. 253-276.

SCOTT, M. WordSmith Tools version 6. Liverpool: Lexical Analysis Software, 2012.

KILGARRIFF, A.; RYCHLY, P.; SMRZ, P.; TUGWELL, D. Sketch Engine (2004), Ambiente Virtual Online. Lexical Computing CZ, 2017. Disponível em: https://www.sketchengine.co.uk. Acesso em: 03 dez. 2017.

WELKER, H. A. Dicionários: uma pequena introdução à lexicografia. Brasília, Thesaurus Editora, 2004.

WELKER, H. A. Panorama Geral da Lexicografia Pedagógica. Brasília: Thesaurus, 2008. 522 p.

WELKER, H. A. Questões de lexicografia pedagógica. In: XATARA, C.; BELIVACQUA, C. R.; HUMBLÉ, P. R. M. (org.). Dicionários na teoria e na prática: como e para quem são feitos. São Paulo: Parábola Editorial, 2011, p. 103-113. (Série: Estratégias de Ensino; 24). 